\title{
IMPLEMENTASI RASPBERRY PI UNTUK RANCANG BANGUN SISTEM KEAMANAN PINTU RUANG SERVER DENGAN PENGENALAN WAJAH MENGGUNAKAN METODE TRIANGLE FACE
}

\author{
Indra Dharma Wijaya ${ }^{1}$, Usman Nurhasan ${ }^{2}$, Mula Agung Barata ${ }^{3}$ \\ 1,2,3 Program Studi Teknik Informatika, Jurusan Teknologi Informasi, Politeknik Negeri Malang \\ ${ }^{1}$ indra.dharma@gmail.com, ${ }^{2}$ usmannurhasan@polinema.ac.id, ${ }^{3}$ mula.ab26@ gmail.com
}

\begin{abstract}
Abstrak
Minicomputer raspberry pi merupakan sebuah alat yang praktis dalam segi dimensi dan memiliki fungsi yang kompleks untuk berbagai kebutuhan fungsi yang akan digunakan oleh manusia sebagai microcontroller, server sampai dengan pengolahan citra digital. Penelitian dilakukan bertujuan untuk membantu memenuhi kebutuhan sistem keamanan ruang server yang mudah untuk diaplikasikan dan murah dalam segi biaya pembuatan dan perawatan serta berteknologi, mengingat pentingnya keamanan data dan informasi yang tersimpan dalam server sehingga perlu pengamanan dalam mengakses ruang server pada suatu perusahaan. Dengan memanfaatkan minicomputer raspberry pi sebagai pemroses dan $u s b$ webcam sebagai alat pendeteksi wajah yang kemudian akan diproses oleh raspberry pi dengan menggunakan OpenCV untuk menentukan wajah manusia atau bukan, lalu wajah tersebut akan masuk pada proses pengenalan wajah dengan metode triangle face yang memanfaatkan perhitungan jarak antar fitur wajah seperti mata, hidung dan mulut. Setelah wajah dikenali maka raspberry pi akan melakukan perintah pada servo untuk membuka pintu ruang agar dapat diakses oleh admin server pada suatu perusahaan. Berdasarkan pengujian sistem yang telah dilakukan, ternyata sistem pengenalan wajah menggunakan metode Triangle Face ini memiliki tingkat keakuratan $75 \%$, kesalahan posistif $25 \%$ dan kesalahan negatif $0 \%$ sehingga dapat disimpulkan bahwa sistem ini cukup aman untuk diaplikasikan dalam sistem keamanan pintu ruang server.
\end{abstract}

Kata kunci: Raspberry Pi, Pengenalan Wajah Open-CV, Triangel Face, Pengolahan Citra

\section{Pendahuluan}

Ruang server merupakan salah satu tempat penyimpanan asset bagi sebuah perusahaan atau kantor besar pada umumnya berupa data-data yang bernilai tinggi bagi perusahaan, pada penelitin ini penulis mengambil studi kasus pada ruang server PPSDM Migas Cepu, karena di dalam ruangan ini terdapat aplikasi dan data kantor yang semakin hari akan semakin bernilai bagi instansi yang bersifat vital dan rahasia, oleh karena itu ruangan ini harus selalu dalam kondisi yang baik. Sebuah ruang server harus memiliki standar mulai suhu udara, kelembaban, kebakaran dan akses masuk dari orang-orang yang tidak berkepentingan. Jadi, tidak semua karyawan memiliki hak akses penuh apalagi dapat dengan mudah keluar masuk ruangan ini.

Biometrik merupakan suatu teknologi yang memanfaatkan ciri khas dari tubuh manusia sebagai pembeda antara 1 orang dengan yang lainnya, misal sidik jari sebagai teknologi finger print, sidik mata, suara sebagai teknologi voice detection dan wajah sebagai teknologi face detection Muhammad M., dkk (2016). Semua teknologi tersebut di atas sudah banyak dikembangkan dalam berbagai aplikasi seperti absensi dan sistem keamanan. Dalam penelitian ini penulis menggunakan wajah sebagai teknologi face detection yang akan diimplementasikan pada sistem keamanan ruang server PPSDM Migas Cepu. Alasan yang melatar belakangi peneliti dalam menggunakan wajah sebagai objek yang akan diidentifikasi sistem karena wajah merupakan bagian tubuh yang dimiliki setiap manusia yang sulit untuk dimanipulasi atau diduplikasi. Namun, dalam penelitian ini memerlukan sistem yang dapat mengenali dan mengidentifikasi wajah setiap orang yang sebelumnya sudah dilakukan perekaman sampel gambar dari masing-masing orang yang memiliki hak akses penuh terhadap ruang server yang sudah lebih dulu tersimpan dalam database. Sistem mengharuskan seseorang untuk tidak bergerak selama wajahnya dalam proses identifikasi agar akurat dalam pembacaannya.

Dalam penelitian ini, peneliti mengusulkan metode triangle face dalam mengidentifkasi atau melakukan klasifikasi wajah dengan webcam lalu menyimpannya ke dalam database dan menggunakan raspberry pi yang merupakan salah satu single board computer sebagai pemrosesnya. 
Metode triangle face mengidentifikasi wajah seseorang dengan mendeteksi jarak-jarak antara mata kanan dengan mata kiri, mata kanan dengan mulut, mata kiri dengan mulut, mata kanan dengan hidung, mata kanan dengan hidung Muhammad M., dkk (2016).

\section{Tinjauan Pustaka}

\subsection{Pengolahan Citra}

Citra (image) merupakan salah satu komponen multimedia yang memegang peranan penting sebagai bentuk informasi visual. Citra mempunyai karakteristik yang tidak dimiliki oleh data teks, yaitu citra kaya dengan informasi, maksudnya sebuah gambar dapat memberikan informasi yang lebih banyak dari pada informasi tersebut disajikan dalam bentuk kata-kata. Citra adalah suat representasi, kemiripan, atau imitasi dari suatu objek. Pengolahan citra adalah pemrosesan citra, khususnya dengan menggunakan komputer, menjadi citra yang kualitasnya lebih baik Apriyana, D., S., M., dkk. Dengan istilah lain bahwa pengolahan citra merupakan proses pengolahan dan analisis citra yang banyak melibatkan persepsi visual.

\subsection{OpenCV}

OpenCV adalah suatu library gratis yang dikembangkan oleh developer-developer Intel Corporation. Library ini terdiri dari fungsi-fungsi computer vision dan API (Aplication Programming Interface) untuk image processing yang high level maupun low level dan sebagai optimasi aplikasi realtime. OpenCV sangat disarankan untuk programmer yang akan berkutat pada bidang computer vision, karena librarynya mampu membuat aplikasi yang handal di bidang digital vision dan mempunyai fitur yang mirip dengan cara pengolahan visual pada manusia Rasyid S., P., dkk (2013).

\subsection{Bahasa Pemograman Python}

Python adalah bahasa pemrograman model skrip (scripting language) yang berorientasi obyek. Python dapat digunakan untuk berbagai keperluan pengembangan perangkat lunak dan dapat berjalan di berbagai platform sistem operasi. Python merupakan bahasa pemrograman yang freeware atau perangkat bebas dalam arti sebenarnya, tidak ada batasan dalam penyalinannya atau mendistribusikannya. Lengkap dengan source codenya, debugger dan profiler, antarmuka yang terkandung di dalamnya untuk pelayanan antarmuka.

\subsection{Raspberry Pi}

Raspberry pi adalah sebuah SBC (singleboard computer) seukuran kartu kredit. raspberry pi telah dilengkapi dengan semua fungsi layaknya sebuah komputer lengkap, menggunakan SOC (System-on-a-Chip) ARM yang dikemas dan diintegrasikan di atas $P C B$ (papan sirkuit). Raspberry $P i$ ini mampu bekerja layaknya komputer pada umumnya dengan kemampuan untuk menjalankan sistem operasi Linux dan aplikasinya seperti LibreOffice, multimedia (audio dan video), peramban web, ataupun programming Rasyid S. P., dkk (2013).

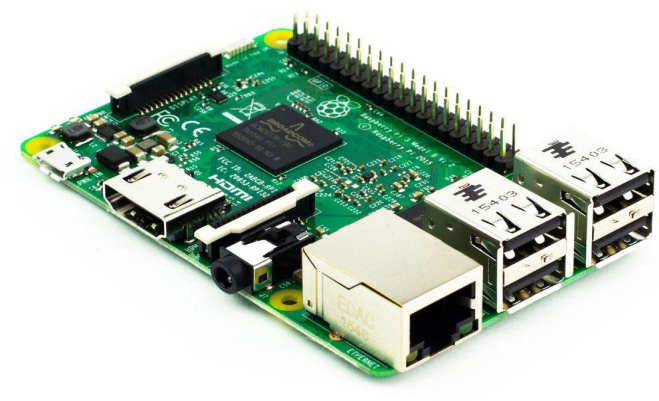

Gambar 1. Raspberry pi

\subsection{Sistem Operasi Raspbian}

Merupakan sebuah sistem operasi berbasis Linux distro Debian yang dapat dioptimalkan untuk penggunaan komputer mini raspberry pi. Sistem operasi ini memiliki beberapa program standard dan beberapa program pembantu untuk dapat menjalankan perangkat keras dari komputer mini raspberry pi ini Rasyid S,. P., dkk (2013).

Dalam sistem operasi ini sudah lebih lengkap daripada sistem yang murni digunakan di komputer pada umumnya karena memiliki lebih dari 350.00 paket dan library precompiled yang tersaji dalam bentuk format yang mudah untuk diinstalisasi pada raspberry pi.

\subsection{Webcam}

Webcam (singkatan dari web camera) adalah sebutan bagi kamera realtime (bermakna keadaan pada saat ini juga) yang gambarnya bisa diakses atau dilihat melalui World Wide Web, program instant messaging, atau aplikasi video call. Sebuah web camera yang sederhana terdiri dari sebuah lensa standar, dipasang di sebuah papan sirkuit untuk menangkap sinyal gambar; casing (cover), termasuk casing depan dan casing samping untuk menutupi lensa standar dan memiliki sebuah lubang lensa di casing depan yang berguna untuk memasukkan gambar; kabel support, yang dibuat 
dari bahan yang fleksibel, salah satu ujungnya dihubungkan dengan papan sirkuit dan ujung satu lagi memiliki connector, kabel ini dikontrol untuk menyesuaikan ketinggian, arah dan sudut pandang web camera.

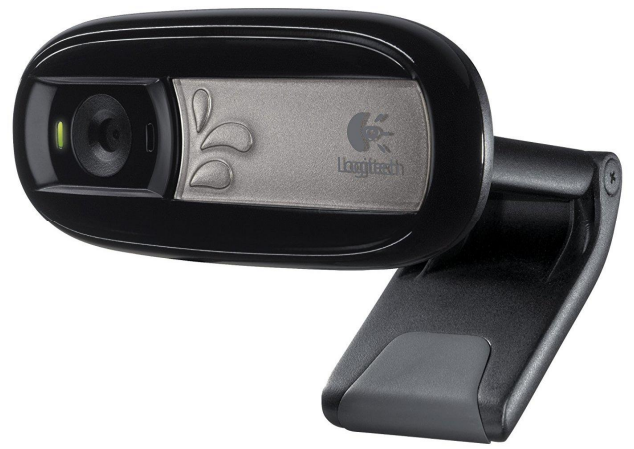

Gambar 2. Web Camera

\subsection{FSWebcam}

FSWebcam adalah suatu aplikasi webcam atau modul kamera yang dapat melakukan ambil gambar melalui media tertentu seperti kamera atau webcam. Aplikasi ini dapat digunakan untuk mereduksi noise yang ditimbulkan oleh kamera saat melakukan perintah ambil gambar dan selain itu aplikasi ini dapat melakukan kompresi ukuran gambar yang dihasilkan berdasarkan format yang diinginkan seperti $P N G$ atau JPEG. Hasil dari proses ambil gambar ini dapat diolah lagi sesuai dengan kebutuhan dan keinginan pengguna, seperti pengaturan resolusi gambar yang diinginkan, info gambar yang ingin ditampilkan pada hasil akhir tangkapan gambar pada kamera, selain itu fswebcam dapat melakukan perintah ambil gambar secara berurutan dan dapat disesuaikan waktu pengambilannya.

\subsection{Raspberry Pi GPIO PIN}

Pin GPIO pada raspberry pi pada adalah interface fisik antara raspberry pi dan perangkat lain yang diintegrasikan. Pada tingkat yang paling sederhana, user bisa menganggapnya sebagai switch yang bisa diaktifkan atau matikan (input) atau piranti bisa dinyalakan atau dimatikan (output). Dari 40 pin, 26 adalah pin GPIO dan yang lainnya adalah pin daya atau ground.

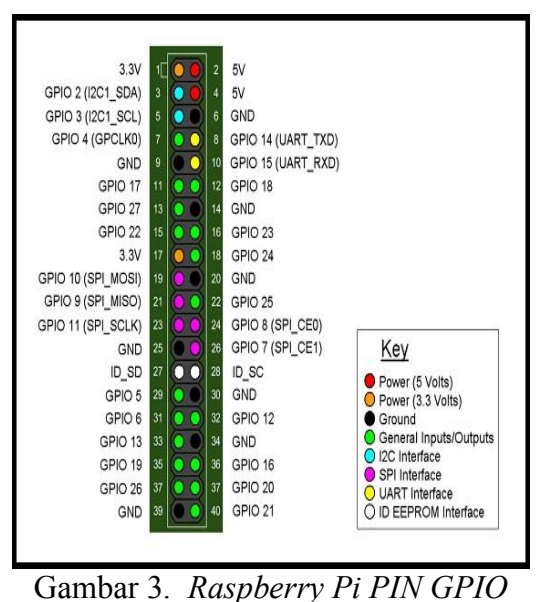

\section{Metodologi}

Pada penelitian ini merupakan penelitian eksperimental yaitu penelitian dengan cara mencatat langsung hasil pengujian sebagai media pengumpulan data termasuk hasil dari analisa kebutuhan sistem. Selanjutnya membuat desain sistem yang akan dirancang, desain yang dirancang meliputi desain perancangan dan skema konfigurasi perangkat lunak maupun perangkat keras yang digunakan dalam perancangan sistem. Lalu mengimplementasikan sistem yang sudah dirancang. Dalam tahap implementasi ini, perancangan sistem yang sudah dibuat kemudian diterapkan sesuai desain yang sudah dibuat. Masing-masing perangkat baik perangkat lunak maupun perangkat keras dihubungkan agar dapat berintegrasi dan membentuk sistem yang sudah dirancang. Setelah tahap implementasi maka dilanjutkan dengan tahap pengujian sistem, bagaimana sistem berjalan dan memperbaiki jika terjadi kekurang akuratan dalam perancangan. Tahapan yang terakhir adalah maintenance, tahapan ini meliputi tahapan pemeliharaan sistem serta pengembangan sistem dalam penambahan fitur sesuai dengan kebutuhan user. Pada gambar 4 di bawah ini menunjukkan tahapan dalam penelitian.

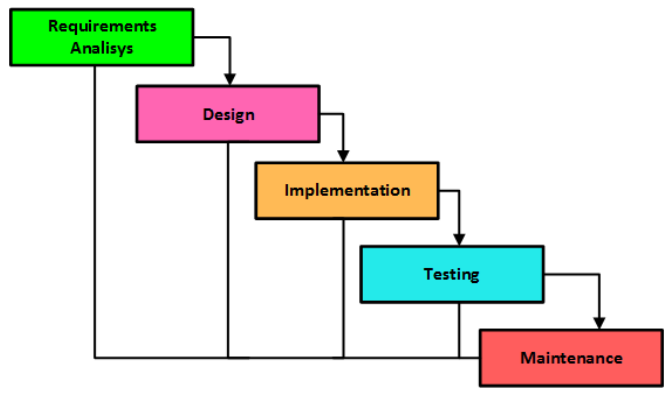

Gambar 4. Tahapan Penelitian

\subsection{Studi Literatur}


Pada tahap ini, peneliti mempelajari berbagai literatur sebagai sumber untuk penelitian melalui pengumpulan data, referensi dari berbagai buku dan sumber dari internet atau sumber lain yang diperlukan dalam merancang dan mengimplementasikan sistem yang dikembangkan dan berkaitan untuk penulisan skripsi ini.

\subsection{Analisa Kebutuhan}

Observasi adalah metode pengumpulan data melalui pengamatan langsung atau peninjauan secara cermat dan langsung di lapangan atau lokasi penelitian. Dalam hal ini, peneliti dengan berpedoman kepada desain penelitiannya perlu mengunjungi lokasi penelitian untuk mengamati langsung berbagai hal atau kondisi yang ada di lapangan. Penemuan ilmu pengetahuan selalu dimulai dengan observasi dan kembali kepada observasi untuk membuktikan kebenaran ilmu pengetahuan tersebut Dinata, A. (2017).

\subsection{Desain Sistem dan Perancangan}

Pada tahap analisa kebutuhan ini merupakan tahapan perencanaan sebelum melakukan penelitian. Peneliti menganalisa segala kebutuhan yang akan digunakan selama proses penelitian meliputi data yang akan diolah, perangkat lunak dan perangkat keras yang akan digunakan.

\subsection{Implementasi}

Tahap desain sistem dan perancangan merupakan tahapan perancangan kerangka kerja yang dibangun dengan mendefiniskan dan menggambarkan sejumlah kerangka akifitas kerja yang diaplikasikan ke semua proyek pengembangan sistem. Model proses yang digambarkan untuk pengembangan sistem dipilih berdasarkan jenis proyek, metode, alat bantu yang digunakan dan perangkat lunak pendukung yang dibutuhkan.

Adapun perancangan yang dibuat adalah sebagai berikut:

a. Block Diagram Sistem

b. Use Case Sistem

c. Skema Konfigurasi Sistem

\subsection{Pengujian}

Pada penelitian ini, pengujian sistem pengenalan wajah yang diimplementasikan pada sistem keamanan pintu ruang server menggunakan metode triangle face sebagai metode pengklasifikasiannya.

Metode triangle face adalah salah satu metode yang digunakan untuk mengenali wajah dalam suatu citra digital. Cara kerja metode ini yaitu dengan cara mendeteksi fitur-fitur wajah seseorang yang telah diinputkan, fitur-fitur wajah ini di jadikan parameter untuk dihitung jarak antar fiturnya yang membentuk segitiga yang sering disebut triangle face. Fitur-fitur wajah tersebut yaitu mata kana, mata kiri, hidung, mulut, tinggi wajah dan lebar wajah. Jarak yang dicari menggunakan fitur-fitur wajah adalah Muhammad M., dkk (2016) :

1. Jarak mata kanan-mata kiri (Mkn - Mkr)

2. Jarak mata kanan-mulut (Mkn - Mt)

3. Jarak mata kiri-mulut ( $\mathrm{Mkr}-\mathrm{Mt})$

4. Jarak mata kanan-hidung $(\mathrm{Mkn}-\mathrm{H})$

5. Jarak mata kiri - hidung $(\mathrm{Mkr}-\mathrm{H})$

Langkah dari proses implementas metode triangle face pada sistem keamana ruang server adalah sebagai berikut:

1. Pendeteksian wajah

2. Pemrosesan wajah

3. Pemrosesan pencarian posisi mata

4. Pemrosesan pencarian posisi hidung

5. Pemrosesan pencarian posisi mulut

6. Pengukuran jarak antar fitur wajah

\section{Analisa dan Perancangan}

\subsection{Gambaran Umum}

Sistem keamanan pintu ruang server yang dibangun bertujuan untuk memberikan pengamanan pada ruang server yang di dalamnya menyimpan data-data perusahaan yang penting dan sangat berharga bagi perusahaan. Pengamanan ruang tersebut tidak menggunakan kunci layaknya pintu pada kamar atau rumah, melainkan menggunakan citra wajah untuk membuka pintu dnegan deteksi kamera yang telah dipasang di dekat pintu.

Proses awal yang dilakukan adalah admin yang diberikan hak akses pada ruang server memposisikan wajah di depan kamera, kemudian kamera akan mendeteksi wajah. Citra wajah yang dideteksi kemudian akan dikenali oleh sistem dan dicocokkan dengan citra yang sebelumnya telah tersimpan dalam database. Jika citra wajah yang dideteksi kamera tidak dikenali sistem, maka sistem meberikan peringatan bahwa citra wajah tidak sesuai. Jika citra wajah sesuai dengan citra yang sebelumnya sudah tersimpan di database maka pintu akan terbuka secara otomatis.

\subsection{Blok Diagram}

Pada blok diagram sistem ini menunjukkan alur dari pendeteksian citra wajah dan pemrosesan citra wajah menggunakan metode triangle face dengan beberapa langkah yang ada pada metode. Tahapan metode dimulai dari objek wajah yang akan dideteksi oleh kamera dan akan diolah oleh sistem pengolahan citra. 


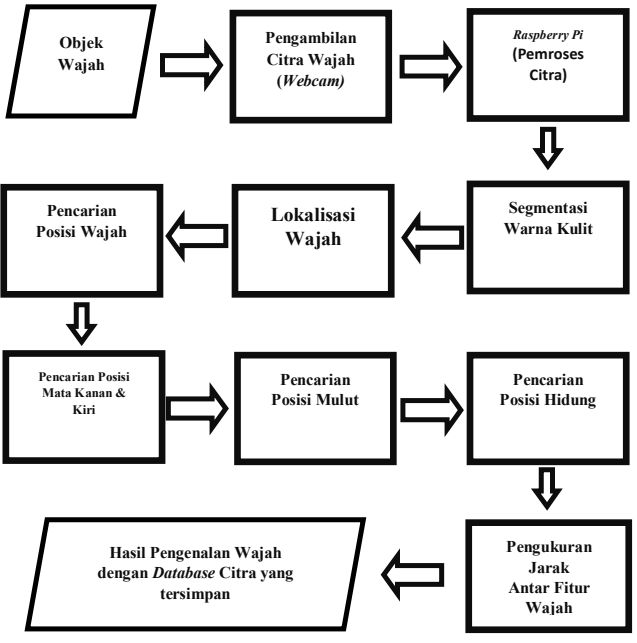

Gambar 5. Blok diagram sistem

\subsection{Use Case Sistem}

Pada gambar 6 di bawah ini merupakan use case dari sistem yang dirancanga. Use case yang dibuat menggambarkan masing-masing aktor yang memiliki hak akses terhadap sistem sesuai dengan level aktor. Pada sistem yang dirancang hanya memiliki 2 aktor, yaitu admin dan users. Admin memiliki hak akses secara menyeluruh terhadap sistem mulai login sistem, tambah data, hapus data dan pendeteksian wajah untuk akses ruang. Users hanya memiliki akses untuk masuk pada ruang server dengan pendeteksian wajah.

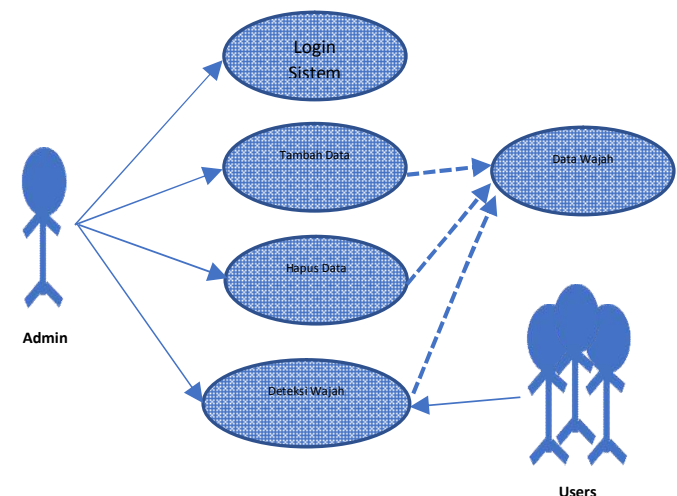

Gambar 6. Use case

\subsection{Skema Konfigurasi Sistem}

Dalam perancangan pemodelan konfigurasi sistem keamanan pintu server ini terdiri dari beberapa perangkat keras yang terinstalasi sesuai dengan konfigurasi yang telah didesain sebelumnya.

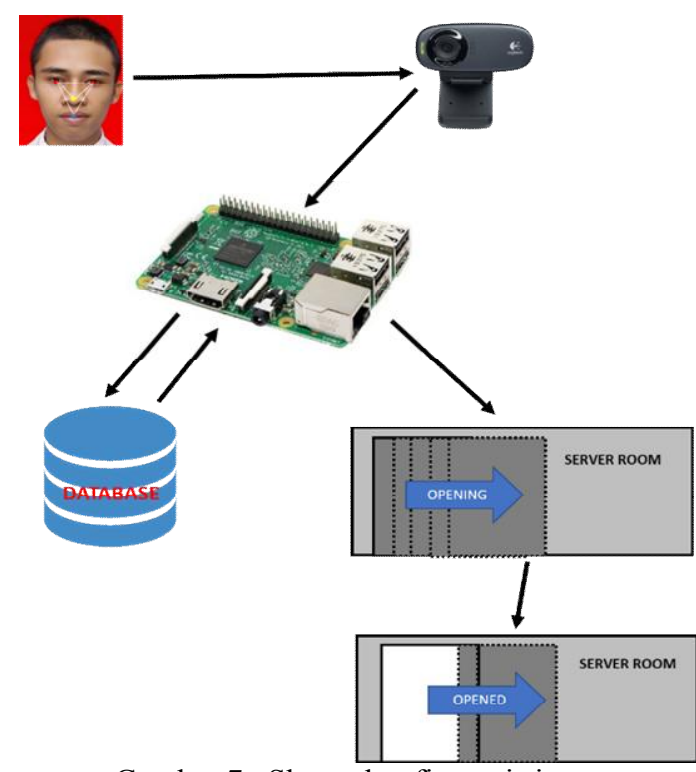

Gambar 7. Skema konfigurasi sistem

\subsection{Analisa Kebutuhan Perangkat Keras}

Pada penelitian ini membutuhkan perangkat keras untuk mengimplementasikan sistem keamanan pintu ruang server sesuai dengan hasil analisa kebutuhan. Adapun perangkat keras meliputi alat dan bahan yang digunakan dalam penelitian ini adalah sebagai berikut:

- Minicomputer raspberry pi

- Acrylic case raspberry pi model B

- USB Adaptor

- VGA to HDMI converter

- Heatsink raspberry pi

- MicroSD card + adapter

- USB Webcam

- Kabel UTP

- Servo motor

- Rainbow Cable 40 cable

- GPIO adapter expansion board 40 PIN

- GPIO bread board

- Kabel jumper

- Kotak simulasi

- Mur baut

- Engsel pintu acrylic

- Kabel ties

\subsection{Analisa Kebutuhan Perangkat Lunak}

Pada penelitian ini membutuhkan perangkat lunak untuk mengimplementasikan sistem keamanan pintu ruang server sesuai dengan hasil analisa kebutuhan. Adapun perangkat lunak yang dalam penelitian ini adalah sebagai berikut:

- Sistem operasi raspbian jessie

- SD Formatter

- Win32 Disk Imager

- PuTTY 
- VNCServer

- Remote Desktop Connection

- FSWebcam

- $\mathrm{OpenCV}$

\section{Implementasi}

\subsection{Instalasi Perangkat Keras}

Semua perangkat dipasang pada papan komponen, kemudian akan dipasang ke dalam kotak simulasi bagian bawah. Dengan 3 mur dan baut sebagai pengait antara papan peralatan dan kotak simulasi. Proses instalasi dapat dilihat pada gambar 8 di bawah ini.

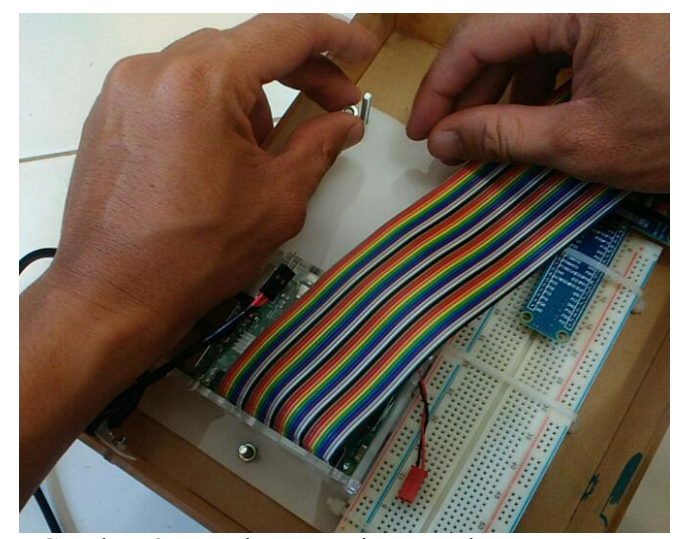

Gambar 8. Implementasi Perangkat Keras

\subsection{Instalasi Perangkat Lunak}

Pada penelitian ini memerlukan perangkat keras yang sudah terpasang perangkat lunak yang digunakan selama penelitian. Instalasi perangkat lunak meliputi instalasi sistem operasi pada raspberry pi hingga instalasi aplikasi yang diperlukan selama penelitian yang memerlukan konfigurasi masing-masing.

Instalasi perangkat lunak pada penelitian ini dilakukan secara bertahap, adapun tahapan dalam instalasi perangkat lunak adalah sebagai berikut:

- Instalasi Raspbian Jessie

- Konfigurasi Raspberry pi

- Instalasi OpenCV

\section{Pengujian \& Pembahasan}

\subsection{Jarak Euclidean}

Pada proses perhitungan jarak antar fitur wajah user akan digunakan rumus jarak Euclidean. Perhitungan jarak Euclidean ditunjukkan pada gambar 9

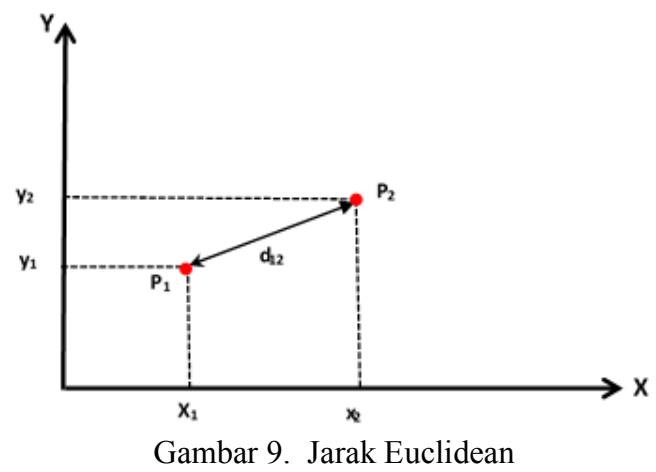

\subsection{Pengujian Aplikasi}

Pada pengujian ini dilakukan untuk mengetahui tingkat keberhasilan pendeteksian wajah, apakah mempunyai tingkat keberhasilan yang tinggi atau tidak berdasarkan rumus yang telah dijabarkan sebelumnya.

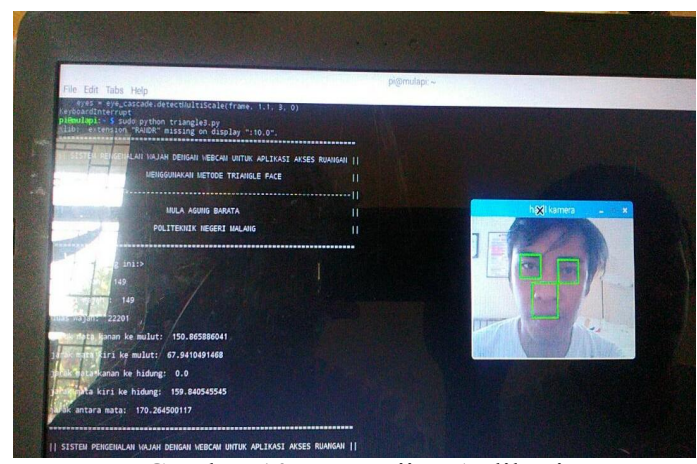

Gambar 10. Pengujian Aplikasi

Tabel 1. Pengukuran jarak antar fitur dengan pengambilan jarak $40 \mathrm{~cm}$

\begin{tabular}{|c|c|l|l|l|}
\hline \multicolumn{5}{|c|}{ Jarak antar Fitur Wajah dalam Pixel } \\
\hline $\begin{array}{c}\text { Ma-Ka } \\
\text { ke } \\
\text { Mulut }\end{array}$ & $\begin{array}{c}\text { Ma-Ki } \\
\text { ke } \\
\text { Mulut }\end{array}$ & $\begin{array}{c}\text { Ma-Ka } \\
\text { ke } \\
\text { Hidung }\end{array}$ & $\begin{array}{c}\text { Ma-Ki } \\
\text { ke } \\
\text { Hidung }\end{array}$ & $\begin{array}{c}\text { Mata ke } \\
\text { Mata }\end{array}$ \\
\hline 193.87 & 117.94 & 63.65 & 59.07 & 78.48 \\
\hline 190.16 & 115.59 & 65.11 & 57.68 & 76 \\
\hline 185.59 & 108.52 & 65.06 & 58.24 & 78.49 \\
\hline 204.54 & 129.32 & 65.06 & 55.80 & 76.99 \\
\hline 189.02 & 116.31 & 60.81 & 53 & 74 \\
\hline 189.87 & 115.86 & 63.65 & 56.30 & 75.49 \\
\hline 181.62 & 104.08 & 65.06 & 54.64 & 73.32 \\
\hline 183.42 & 110.23 & 64.67 & 55.54 & 74.34 \\
\hline 184.62 & 102.07 & 66.08 & 53.67 & 73.40 \\
\hline 187.49 & 110.53 & 67.05 & 59.27 & 78.46 \\
\hline
\end{tabular}

\subsection{Pengukuran Tingkat Akurasi Sistem}

Dalam setiap pengujian sistem menggunakan 30 sampel dari 9 orang maka akan dibuat persentase keakuratan dari sistem tersebut, untuk mengetahui persentase sistem ini maka hasil pengujian di atas dapat dimasukkan dalam persamaan berikut ini: 


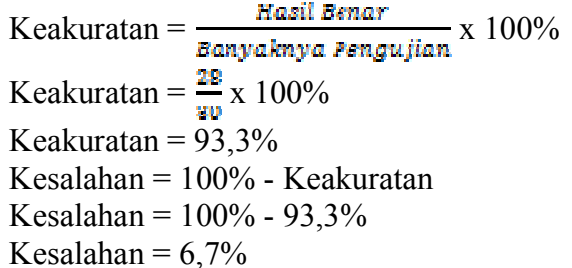

Dari perhitungan di atas menunjukkan hasil dari kerja sistem pengenalan wajah, didapatkan 93,3\% keakuratan dan 6,7\% kesalahan. Namun kesalahan yang didapatkan merupakan kesalahan positif. Kesalahan positif adalah kesalahan sistem yang dipakai namun tidak berakibat fatal pada keamanan laptop.

\section{Kesimpulan dan Saran}

\subsection{Kesimpulan}

Hasil uji coba dari implementasi minicomputer raspberry pi untuk sistem keamanan pintu ruang server dapat ditarik kesimpulan sebagai berikut:

1. Implementasi minicomputer raspberry pi untuk penerapan pengolahan citra dirasa belum bisa optimal dalam kinerjanya dilihat dari CPU Usage ketika aplikasi computer vision dijalankan sangat menguras $C P U$ dan memory.

2. Sistem pengenalan wajah dapat dilakukan dengan metode triangle face dengan membandingkan jarak antar fitur wajah.

3. Pada sistem yang dibuat, proses pendeteksian fitur wajah seperti kedua mata, hidung dan mulut sangat sulit dilakukan karena kinerja perangkat keras sangat berat.

4. Sistem yang dibuat sulit mendapatkan nilai jarak yang sama persis dalam satu objek wajah, hal ini dikarenakan sulitnya proses pendeteksian fitur wajah yang sesuai.

5. Intensitas cahaya sangat mempengaruhi nilai jarak antar fitur yang diambil, sehingga data training dan testing dalam pengambilannya harus memiliki intensitas cahaya yang sama.

6. Sistem yang dibuat cukup aman untuk diimplementasikan untuk sistem keamanan pintu ruang server

\subsection{Saran}

Saran yang diberikan penulis dalam mengembangkan penelitian berikutnya antara lain:

a. Pengolahan citra kurang cocok menggunakan perangkat keras minicomputer raspberry pi sebagai pengolahnya, dikarenakan pengolahan citra memerlukan spesifikasi komputer yang cukup tinggi untuk mengimbangi kinerja yang cukup berat. b. Pengambilan citra dengan metode triangle face dirasa sangat kaku dan kurang fleksibel, pengambilan citra dilakukan dengan meletakkan dagu pada penyangga dagu dan dibatasi oleh jarak pengambilan wajah, seharusnya pengambilan citra tidak terpaku pada penyangga dagu dan jarak pengambilan.

c. Sebaiknya kamera yang digunakan memiliki resolusi minimal 8 megapiksel agar menghasilkan kualitas data training yang baik karena hal itu menentukan keakurasian sistem dalam mengenali wajah.

\section{Daftar Pustaka:}

Muhammad Miftah, Aripin. "Pengamanan Laptop Menggunakan Pengenalan Wajah Berbasis Triangle Face", Journal of Applied Intelligent System, Vol.1, pp. 22-35, Feb. 2016.

Rasyid Sindu Prihantono, Ary Mahzaruddin Shiddiqi., S.Kom., M.Comp.Sc., Hudan Studiawan, S.Kom.,M.Kom., "Rancang Bangun Sistem Keamanan dan Pengenalan Objek dalam Ruangan Sebagai Pengganti CCTV dengan Menggunakan Raspberry Pi”, JURNAL TEKNIK POMITS, Vol. 2, pp. 2301-9271, 2013.

Therzian Richard Perkasa, Helmy Widyantara, "Pauladie Susanto. Rancang Bangun Pendeteksi Image Subtraction Pada Single Board Computer (SBC)", Journal of Control and Network Systems, Vol. 3, pp. 90-97, 2014.

Fadli Sirait, Yoserizal, "Pemanfaatan Raspberry Pi Sebagai Processor Pada Pendeteksian Dan Pengenalan Pola Wajah", Vol. 7, pp. 20869479, Sept. 2016.

Apriyana, Delta Sri Maharani, Shinta Puspitasari, Renni Angreni. "Perbandingan Model Sobel, Metode Prewitt dan Metode Robert Untuk Deteksi Tepi Objek Pada Aplikasi Pengenalan Bentuk Berbasis Citra Digital.

Dinata, Andi. 2017. Physical Computing dengan Raspberry Pi. Jakarta: Elex Media Komputindo. 
Volume 4, Edisi 1, November 2017

$\mathbf{1 6} \mid \mathrm{H}$ a 1 a $\mathrm{m}$ a $\mathrm{n}$ 